\title{
AIR POLLUTION AND CHEST DISEASES - A REVIEW
}

\author{
TASKINA ALI ${ }^{1}$, MD. ALI HOSSAIN², KAZI SAIFUDDIN BENNOOR 3
}

Assistant Professor, Department of Physiology, Comilla Medical College ${ }^{1}$, Associate Professor of Respiratory Medicine, National Institute of Diseases of the Chest \& Hospital, Mohakhali, Dhaka-1212², Registrar (Medicine), National Institute of Diseases of the Chest \& Hospital, Mohakhali, Dhaka-1212 ${ }^{3}$

\begin{abstract}
Ambient (outdoor) air pollution is now recognized as an important problem, both nationally and worldwide. Our scientific understanding of the spectrum of health effects of air pollution has increased, and numerous studies are discovering important health effects from air pollution at levels once considered safe. Elderly, children and infants are among the most susceptible to many of the air pollutants. In addition to associations between air pollution and respiratory symptoms, asthma exacerbations, and asthma hospitalizations, recent studies have found links between air pollution and preterm birth, infant mortality, deficits in lung growth, and possibly, development of asthma. This paper summarizes the recent literature linking ambient air pollution to adverse health outcomes in population and includes a perspective on the current regulatory process. The review provides advice to pediatricians on how to integrate issues regarding air quality and health into patient education and patients' environmental health advocacy and concludes with recommendations to the government on promotion of effective air-pollution policies to ensure protection of our health.
\end{abstract}

(Bangladesh J Physiol Pharmacol 2006; 22(1/2) : 25-28)

\section{INTRODUCTION}

Fresh air is a precious and indispensable gift of the nature. Major air pollution episodes earlier this century provided clear evidence of the adverse human health consequences of elevated outdoor pollutants level in air. This striking increase in daily mortality and hospitalizations were observed in London during and following the famous fog episode of December 1952 , which especially affected the old and the sick people. ${ }^{1}$ Table 1 denotes the notable air pollution episodes of last two centuries worldwide.

Notable air pollution episodes of last two centuries. ${ }^{1}$

\begin{tabular}{llcc}
\hline Location & Date & Pollutants & Death \\
\hline London, England & Dec. 9-11, 1873 & $\mathrm{SO}_{2}$ & 650 \\
Meuse Valley, Belgium & Dec. 1-5, 1930 & $\mathrm{SO}_{2}$ & 1176 \\
Donora PA, USA & Oct. 26-31, 1948 & $\mathrm{SO}_{2}$ & 700 \\
Poza Rica, Mexico & Nov. 24, 1950 & $\mathrm{H}_{2} \mathrm{~S}$ & 22 \\
London, England & Dec. 5-9, 1952 & $\mathrm{SO}_{2}$ & 4000 \\
London, England & Jan. 3-6, 1966 & $\mathrm{SO}_{2}$ & 1000 \\
New York, USA & Nov. 24-30, 1966 & $\mathrm{SO}_{2}$ & 168 \\
\hline
\end{tabular}

Public concern regarding the human health effects of outdoor air pollution, motivated by episodes like these and causes the development of air quality regulations. In

Address of Correspondence: : Dr. Taskina Ali, Assistant Professor, Department of Physiology, Comilla Medical College, Comilla the United States, the federal Clean Air Act of 1970 created the U.S. Environmental Protection Agency (U.S. EPA) and established for the first time nationwide standards for outdoor air quality. The following table shows the National Ambient Air Quality Standards (NAAQS) for "criteria pollutants,"

\section{National Ambient Air Quality Standards for Criteria Air} Pollutants, 1997,2

\begin{tabular}{|c|c|}
\hline Pollutant & Primary Standards* \\
\hline \multicolumn{2}{|l|}{ Ozone } \\
\hline 1-h average & $0.12 \mathrm{ppm}\left(235 \mu \mathrm{g} / \mathrm{m}^{3}\right)$ \\
\hline 8-h average & $0.08 \mathrm{ppm}\left(157 \mu \mathrm{g} / \mathrm{m}^{3}\right)$ \\
\hline \multicolumn{2}{|l|}{ Carbon monoxide } \\
\hline 8-h average & $9 \mathrm{ppm}\left(10 \mu \mathrm{g} / \mathrm{m}^{3}\right)$ \\
\hline $1-\mathrm{h}$ average & 35 ppm $\left(40 \mu \mathrm{g} / \mathrm{m}^{3}\right)$ \\
\hline \multicolumn{2}{|l|}{ Sulfur dioxide } \\
\hline Annual arithmetic mean & $0.03 \mathrm{ppm}\left(80 \mu \mathrm{g} / \mathrm{m}^{3}\right)$ \\
\hline 24-h average & $0.14 \mathrm{ppm}\left(365 \mu \mathrm{g} / \mathrm{m}^{3}\right)$ \\
\hline$P M_{10}$ & \\
\hline Annual arithmetic mean & $50 \mu \mathrm{g} / \mathrm{m}^{3}$ \\
\hline 24-h average & $150 \mu \mathrm{g} / \mathrm{m}^{3}$ \\
\hline \multicolumn{2}{|l|}{$\mathrm{PM}_{2.5}$} \\
\hline Annual arithmetic mean & $15 \mu \mathrm{g} / \mathrm{m}^{3}$ \\
\hline 24-h average & $65 \mu \mathrm{g} / \mathrm{m}^{3}$ \\
\hline \multicolumn{2}{|l|}{ Nitrogen dioxide } \\
\hline $\begin{array}{l}\text { Annual arithmetic mean } \\
\text { Lead }\end{array}$ & $0.053 \mathrm{ppm}\left(100 \mu \mathrm{g} / \mathrm{m}^{3}\right)$ \\
\hline Quarterly average & $1.5 \mu \mathrm{g} / \mathrm{m}^{3}$ \\
\hline
\end{tabular}

* People residing in regions with pollutant concentrations above the primary standard may experience adverse health effects from poor air quality. 
But, in comparison to the NAQQS the ambient air quality standards for different pollutants are much higher under the Bangladesh Environment Conservation Rules, 1997, which are denoted in the following table:

\section{Ambient Air Quality Standards (Concentration in $\left.\mu g / m^{3}\right){ }^{3}$}

\begin{tabular}{lcccc}
\hline Area Category & $\mathrm{SPM}$ & $\mathrm{SO}_{2}$ & $\mathrm{CO}$ & $\mathrm{NO}_{2}$ \\
\hline Industrial & 500 & 120 & 5000 & 100 \\
Commercial & 400 & 100 & 5000 & 100 \\
Residential \& Rural & 200 & 80 & 2000 & 80 \\
Sensitive & 100 & 30 & 1000 & 30 \\
\hline
\end{tabular}

The major source of air pollution in developing countries like Bangladesh is traffic vehicles of 2 stroke 3 wheelers. However, industries, small manufacturing units, construction works, earth digging, open burning (cooking etc.). brick fields, aerosols, machineries (generators, photocopiers), open drainage and waste disposal, cigarette smoking, insecticides are also the culprits of air pollution.

\section{Particulate matter (PM)}

$P M_{10}$ is a heterogeneous mixture of small solid or liquid particles of varying composition found in the atmosphere. Fine particles ( $\left.P M_{2.5}\right)$ are emitted from combustion processes (especially diesel-powered engines, power generation, and wood burning) and from some industrial activities. Coarse particles (diameter between 2.5 and 10 micron $\mathrm{m}$ ) include windblown dust from dirt roads or soil and dust particles created by crushing and grinding operations. Toxicity of particles may vary with composition. ${ }^{4}$

$\mathrm{PM}_{2.5}$ represents the mass concentration of airborne particles with aerodynamic diameters smaller than 2.5 micro m. PM $_{2.5}$ particles vary widely in size, composition, and origin. Some are emitted directly by fossil fuel combustion, such as fly ash and soot from coal and diesel fuel combustion. Other forms as secondary pollutants by chemical reactions in the atmosphere that convert gases emitted by fossil fuel combustion, such as sulfur dioxide, to particles, such as acid sulfates. Although all particles less than $2.5 \mu \mathrm{m}$ diameter are capable upon inhalation of reaching the deepest portions of the lung, particles less than $0.1 \mathrm{~mm}$ diameter have a higher likelihood of depositing in the deep lung, because of their high diffusion coefficients ${ }^{5}$. However, because particle mass increases as the third power of diameter, large-diameter particles tend to dominate measurements of $P M_{2.5}$, which are reported in units of micrograms of particles per cubic meter of air.
Important chemical components of $\mathrm{PM}_{2.5}$ include sulfates, nitrates, elemental carbon, organic molecules, and a variety of trace elements ${ }^{5}$.

Outdoor $\mathrm{PM}_{2.5}$ particles penetrate readily to the indoor environment ${ }^{6}$. Unlike ozone, significant indoor sources of $\mathrm{PM}_{2.5}$ exist, the most prominent being smoking and cooking ${ }^{6}$.

\section{Ozone}

Ozone is a natural constituent of air, existing in equilibrium with oxygen In the stratosphere, it filters out ultraviolet light and therefore from the human point of view serves a useful function. In the lower atmosphere it exists in lower concentrations by the photochemical reactions on volatile organic compounds produced by plants together with intrusion of gas from thunderstorms. The photochemical reductions of nitrogen dioxide produces nitric oxide and an oxygen radical; the combination of this oxygen radical with oxygen causes ozone formation; the reductions of ozone by nitric oxide to reform nitrogen dioxide and oxygen. Thus, in a steady state condition, there is always equilibrium between oxygen, ozone and nitrogen dioxide. Introduction of large quantities of nitrogen dioxide or volatile organic compounds into this system moves the equilibrium towards the greater production of ozone ${ }^{7}$.

These photochemical reactions are dependent on presence and intensity of sunlight. So ozone is a more important pollutant in sunnier climate, that is, in southern than northern climates. Again, these photochemical reactions takes some time to occur and for that reason is higher in distant from site of production of primary pollutant. It pollutes the downhill urban area, countryside and sunburn areas ${ }^{7}$.

\section{Sulpher dioxide}

Sulpher dioxide is produced by, combustion of fossil fuel, coal and oil and naturally by volcanic activity ${ }^{7}$. Sulpher dioxide in atmosphere is oxidized to Sulpher trioxide and then hydrolyzed to sulphuric acid. It is important in the place of coal burning, larger rural plants and countryside downwind of the source ${ }^{7}$.

\section{Nitrogen dioxide}

Nitrogen dioxide is a gaseous pollutant, produced by, high temperature combustions, volcano, and thunderstorm, fuel combustion in vehicle and industrial process and bacteria. It is the main gaseous pollutant of indoor ${ }^{7}$.

\section{Effects of Air Pollution}

As children spend more time in outdoors than do adults, they have increased exposure to outdoor air pollution and are more vulnerable to the adverse effects 
of air pollution than adults. Different studies showed that, $80 \%$ of alveoli are formed postnatally and changes in the lung continue through adolescence and the developing lung is highly susceptible to damage after exposure to environmental toxicants during this early childhood ${ }^{8}$. In adults, air pollution is associated with respiratory and cardiovascular hospitalization, cardiovascular mortality and lung cancer ${ }^{9}$.

\section{Particulate matter}

Particle pollution contributes to excess mortality and hospitalizations for cardiac and respiratory tract disease ${ }^{9}$. The mechanism for particulate matter-associated cardiac effects may be related to disturbances in the cardiac autonomic nervous system, cardiac arrhythmias, or increased blood concentrations of markers of cardiovascular risk (eg, fibrinogen) ${ }^{9}$. In children, they are also associated with deficits in lung growth (as measured by lung function tests) ${ }^{10}$. Recent studies in different countries have also found associations between ambient particulate pollution and post neonatal infant mortality, low birth weight and preterm birth ${ }^{11}$.

\section{Ozone}

Ozone is a powerful oxidant and respiratory tract irritant in adults and children, causing shortness of breath, wheezing, cough and chest pain when inhaling deeply ${ }^{12}$. By experimental study, it has been shown that ozone is a pulmonary irritant causing increase in bronchial resistance and reactivity in relation to the dose inhaled ${ }^{13}$. Children have decrease in lung function, increase in respiratory tract symptoms, and asthma exacerbations with emergency department visits for asthma and school absences on days with higher levels of ambient ozone ${ }^{10}$. In healthy adults, ozone causes airway inflammation and hyper reactivity, decrements in pulmonary function, and increased respiratory tract symptoms ${ }^{11}$. Ozone inhalation also decreases the allergen conc. at which sensitized people react ${ }^{11}$.

\section{Sulpher dioxide}

By an experimental study, it has been shown that the ventilatory function of healthy volunteers falls after inhalation of concentration around $5000 \mathrm{ppb}$, while asthmatic individuals may respond at about $200 \mathrm{ppb}$ or lower, depending on severity ${ }^{13}$. There is also evidence of increasing the risk of exacerbation of chronic lung diseases also ${ }^{13}$.

\section{Nitrogen dioxide}

A controlled-exposure study in asthmatic people showed that short-term exposures (30 minutes) to nitrogen dioxide at concentrations as low as $0.26 \mathrm{ppm}$ can enhance the allergic response ${ }^{13}$. Different epidemiological studies have reported relationships between increased ambient nitrogen dioxide and risks of respiratory tract symptoms 14,15 .

\section{Prevention}

To improve air quality public health interventions is necessary. A decrease in levels of air pollutant in former East Germany after reunification was associated with a decrease in bronchitis and improved lung function 16,17. During the 1996 Summer Olympics in Atlanta, Georgia, extensive programs were implemented to improve mass transportation and also to decrease anticipated downtown traffic congestion. These programs were successful and were associated with a prolonged decrease in ozone pollution and significantly lower rates of childhood asthma attacks during this period ${ }^{18}$. Lung function improved in children who moved away from communities with high particulate air pollution, compared with those who remained or moved to communities with comparable particulate air pollution ${ }^{19}$. These studies provide support for continued efforts to decrease air pollution and improve health. Dietary factors may play a role in modulating the effects of air pollution in children. A recent study in Mexico City showed that children with asthma given antioxidant supplements were less affected by pollutant air than those of without supplementation ${ }^{20}$. In USA, for the protection of public health, the EPA (Environmental Protection Agency) established the National Ambient Air Quality Standards (NAQQS) (Table 1), which are reviewed every five years and set to protect public health. These standards are set on the basis of numerous scientific studies showing that the previous standards were not adequate to ensure health protection. There is also an air quality index (AQI), which provides the local information on air quality and levels of different air pollutants ${ }^{2}$. The AQI is reported daily in metropolitan areas, often as part of local weather forecasts on television or radio or in newspapers. In the developing countries like Bangladesh these types of measures can be useful as a preventive measure for pollutant caused disease exacerbation.

\section{Strategies for control of air pollution}

Total elimination of air pollution is an unrealistic or impossible goal. So measures needed to identify the nature and source of the specific pollutants responsible and also to reduce their production and dispersal. The environmental pollution can be controlled by primary, secondary and tertiary prevention.

\section{Primary Prevention:}

Primary prevention means abrogating the risk factor before illness strikes. It includes banning of certain hazards, for example, two stroke scooters, unplanned industrialization, etc.

\section{Secondary Prevention:}

Secondary prevention means the identification of the people at risk and the diseased and also the avoidance of further deterioration of their illness. The pulmonary 
clinicians have more opportunities for secondary than primary preventive interventions.

\section{Tertiary Prevention:}

Tertiary prevention means the activities to slow the progression of complications of previous exposure or of disease that is already established, e.g. smoking cessation among asbestos workers, Tuberculosis prophylaxis among the silicatics.

\section{CONCLUSION}

Environmental pollution comprises an important and challenging topic in respiratory medicine. Their diagnosis, treatment and most prominently their prevention have major public health implications. The present day environment crisis demands a change in public attitude to rescue the environment from destruction. Industrialized nations have a big share in the present day environment problems.

In developing countries like Bangladesh, environmental protection is still a luxury and hard to afford. Some are finally becoming aware of the environment abuse, but a large part of population, foreign debts and unplanned industrialization have kept them off the environment conservation process.

The situation may improve only when people realize that there are certain rules that they must go by to protect the environment. In Bangladesh, we should strictly abide by the "Environment Conservation Act 1995" and the "Environment Conservation Rules 1997". Side by side, awareness programs should be taken up by the Government and non-government organizations through mass media, especially Radio and Television. Concerted efforts like epidemiological and experimental studies should be organized involving multi-discipline peoples like Scientists, Doctors, Engineers, Lawyers and Journalists etc.

Without control of environmental pollution, present situation will be worse in near future and will push the world towards a corner, making the proposition uncertain whether or not it will remain habitable for coming generations.

\section{REFERENCES:}

1. Logan WPD. Mortality in London fog incident, 1952. Lancet1953;264:336-338

2. US Environmental Protection Agency. Latest findings on national air quality: 2000 status and trends. Research Triangle Park, NC: Environmental ProtectionAgency; 2001. Publication No. EPA 454/K-01-002. Available at: www.epa.gov/airtrends/ reports.html. Accessed August 8, 2003

3. Asian Development Bank. Urban Air Quality Management and Practice in Asian Cities: Dhaka, 2001

4. Pandya RJ, Solomon G, Kinner A, Balmes JR. Diesel exhaust and asthma: hypotheses and molecular mechanisms of action. Environ Health Perspect. 2002;110(suppl 1):103-112

5. Spengler J, Wilson R. Emissions, dispersion, and concentrationof particles. In Wilson R, Spengler JD, eds.
Particles inOur Air: Concentrations and Health Effects. HarvardSchool of Public Health, 1996; 000-000

6. Ozkaynak $H$, Spengler J. The role of outdoor particulate matterin assessing total human exposure. In Wilson R, SpenglerJD, eds. Particles in Our Air: Concentrations and Health Effects. Harvard School of Public Health, Cambridge, MA:Harvard University Press 1996; 41-62

\section{Crofton 329}

8. Dietert RR, Etzel RA, Chen D, et al. Workshop to identify critical windows of exposure for children's health: immune and respiratory systems work roup summary. Environ Health Perspect. 2000;108(suppl 3):483-490

9. Dockery DW. Epidemiologic evidence of cardiovascular effects of particulate air pollution. Environ Health Perspect. 2001;109(suppl 4): 483-486

10. Hoek G Dockery DW, Pope A, Neas L, Roemer W, Brunekreef B. Association between PM10 and decrements in peak expiratory flow rates in children: reanalysis of data from five panel studies. Eur Respir J. 1998;11:1307-1311

11. Bobak M. Outdoor air pollution, low birth weight, and prematurity. Environ Health Perspect. 2000;108:173-176

12. American Thoracic Society, Committee of the Environmental and ccupational Health Assembly. Health effects of outdoor air pollution. Part 1. Am J Respir Crit Care Med. 1996;153:3-50

13. Department of Health Advisory Group on the Medical Aspects of Air Pollution Episodes. First Report: Ozone. London: HMSO, 1991.

14. Strand V, Svartengren M, Rak S, Barck C, Bylin G. Repeated exposure to an ambient level of NO2 enhances asthmatic response to a nonsymptomatic allergen dose. Eur Respir J. 1998;12:6-12

15. Hajat S, Haines A, Goubet SA, Atkinson RW, Anderson HR. Association of air pollution with daily GP consultations for asthma and other lower respiratory conditions in London. Thorax. 1999;54:597-605

16. Shima M, Adachi M. Effect of outdoor and indoor nitrogen dioxide on respiratory symptoms in schoolchildren. Int $\mathrm{J}$ Epidemiol. 2000;29: 862-870

17. Heinrich J, Hoelscher B, Wichmann HE. Decline of ambient air pollution and respiratory symptoms in children. Am J Respir Crit Care Med. 2000;161:1930-1936

18. Frye C, Hoelscher B, Cyrys J, Wjst M, Wichmann HE, Heinrich J. Association of lung function with declining ambient air pollution. Environ Health Perspect. 2003;111:383-387

19. Friedman MS, Powell KE, Hutwagner L, Graham LM, Teague WG. Impact of changes in transportation and commuting behaviors during the 1996 Summer Olympic Games in Atlanta on air quality and childhood asthma. JAMA. 001;285:897-905

20. Avol EL, Gauderman WJ, Tan SM, London SJ, Peters JM. Respiratory effects of relocating to areas of differing air pollution levels. Am J Respir Crit Care Med. 001;164:20672072

21. Romieu I, Sienra-Monge JJ, Ramirez-Aguilar M, et al. Antioxidant supplementation and lung functions among children with asthma exposed to high levels of air pollutants. Am J Respir CritCare Med. 2002;166:703-709. 